\title{
Identification of immediate early gene $X-1$ as a cellular target gene of hcmv-mir-UL148D
}

\author{
YUE-PING WANG, YING QI, YU-JING HUANG, MAN-LONG QI, YAN-PING MA, \\ RONG HE, YAO-HUA JI, ZHENG-RONG SUN and QIANG RUAN
}

\begin{abstract}
Virus Laboratory, The Affiliated Shengjing Hospital, China Medical University, Shenyang, Liaoning 110004, P.R. China
\end{abstract}
Received November 14, 2012; Accepted January 23, 2013

DOI: $10.3892 /$ ijmm.2013.1271

\begin{abstract}
Human cytomegalovirus (HCMV) is a herpesvirus that causes congenital diseases and opportunistic infections in immunocompromised individuals. Its functional proteins and microRNAs (miRNAs) facilitate efficient viral propagation by altering host cell behavior. The identification of functional target genes of miRNAs is an important step in the study of HCMV pathogenesis. HCMV encodes at least 14 miRNAs, including hcmv-mir-UL148D, which resides in the HCMV $\mathrm{UL} / \mathrm{b}$ ' region. hcmv-mir-UL148D is the only miRNA encoded by the HCMV UL/b' region; however, its targets and functional effects have not yet been eludidated. In this study, hybrid-PCR screening was used to identify target genes and dual luciferase reporter assay was used to evaluate the binding effect of hcmv-miR-UL148D to the 3' untranslated region (3'UTR) of IEX-1. In addition, western blot analysis was used to detect the expression kinetics of IEX-1 protein and apoptosis assay was used to identify the effects of hcmv-miR-UL148D on cell apoptosis. The hybrid-PCR results showed that only one binding site in the 3'UTR of the cellular gene, human immediate early gene X-1 (IEX-1), was completely complementary to an 11 nucleotide (nt) sequence in the 5 terminus of hemvmir-UL148D, including the entire seed region. The binding site was demonstrated to be functional by dual luciferase reporter assay with a $47 \%$ repression of the relative luciferase activity. In an in vitro system of human embryonic kidney 293 (HEK293) cells, the ectopically expressed hcmv-mir-UL148D exhibited a downregulatory effect on IEX-1 expression, and decreased the cell apoptosis induced by transfected IEX-1. Our data demonstrate that homv-mir-UL148D targets the cellular gene, IEX-1, downregulating its expression and thus results in anti-apoptotic effects.
\end{abstract}

Correspondence to: Professor Qiang Ruan, Virus Laboratory, The Affiliated Shengjing Hospital, China Medical University, 36 Sanhao Street, Shenyang, Liaoning 110004, P.R. China

E-mail: ruanq@sj-hospital.org

Key words: human cytomegalovirus, microRNAs, hcmv-mirUL148D, binding site, immediate early gene X-1, anti-apoptosis

\section{Introduction}

Human cytomegalovirus (HCMV) is an ubiquitous $\beta$-herpesvirus, which is able to maintain a persistent or latent infection during the host's lifetime. It always displays asymptomatic infection in healthy adults, and also causes significant morbidity and mortality in newborn and immunocompromised patients (1). HCMV genomic DNA comprises $\sim 230 \mathrm{~kb}$ and potentially encodes $\sim 165$ open reading frames (ORFs) (2). Compared with the genome of the prototype laboratory strain, AD169, genomes of low-passage HCMV clinical isolates contain the UL/b' region, including ORFs UL133-UL151, considered as a critical candidate cluster to clinical pathogenesis (3). Although the $\mathrm{UL} / \mathrm{b}^{\prime}$ region is not essential to viral growth or replication (4), products of this region, including UL141, UL142 and UL144 have been experimentally identified to aid in viral escape from immune surveillance through interactions with cellular molecules (5-10).

A number of previous studies have demonstrated that a species of regulatory RNA molecules, known as microRNAs (miRNAs), are encoded in non-coding regions and are involved in the regulation of diverse cellular processes such as development, differentiation, cell cycle, apoptosis and immune responses (11-13). miRNAs display their post-transcriptional regulation through RNA interference by 2 different mechanisms (14-17). Binding within the first 10 bases of a miRNA, particularly within bases 2 to 7 at the $5^{\prime}$ end of the miRNA known as the seed region, is considered of particular importance (18-20).

HCMV encodes at least 14 miRNAs expressed in 11 unique RNA structures $(14,21)$. Unlike other miRNAs expressed in herpesviruses in the clustered form, 14 miRNAs encoded by the HCMV are scattered in the whole genome. The target transcripts and regulatory functions of HCMV miRNAs remain to be elucidated. Only some HCMV miRNAs, such as hcmv-miRUL112 $(22,23)$ and homv-miR-US4-1 (24) have been verified experimentally to be involved in viral pathogenesis by inhibiting host immune molecules or regulating viral proteins. As the only miRNA expressed in the HCMV UL/b' region, identifying the target genes and regulatory functions of hcmv-miR-UL148D may provide further insight into the viral pathogenesis of clinical isolates $(25,26)$.

In this study, we identified and characterized the functional targets of hcmv-miR-UL148D using a hybrid-PCR approach 
in combination with luciferase report assays and western blot analysis. The cellular target gene, human immediate early gene X-1 (IEX-1), was identified as the target of homv-miR-UL148D. The suppression of IEX-1 expression by hemv-miR-UL148D in an in vitro system was primarily investigated for the antiapoptotic effect on host cells.

\section{Materials and methods}

Cell line and cell culture. Human embryonic lung fibroblast (HELF) and human embryonic kidney 293 (HEK293) cells were obtained from Shanghai Biology Institution (Shanghai, China). The HELF and HEK293 cells were cultured in RPMI-1640 or DMEM supplemented with L-glutamine and pennicilin/streptomycin with $10 \% \mathrm{FBS}$ at $37^{\circ} \mathrm{C}$ and $5 \% \mathrm{CO}_{2}$ in a humidified incubator.

Virus, RNA and complementary DNA (cDNA) preparation. A HCMV clinical strain, termed Han, was isolated from a urine sample of an infant ( $<5$ months old) hospitalized in Shengjing Hospital of China Medical University, Shenyang, China. The strain has been passaged 6 times in HELF cells before being used in this study.

For preparation of immediate early (IE) RNA, cycloheximide $(100 \mu \mathrm{g} / \mathrm{ml})$ was added to the culture medium $1 \mathrm{~h}$ prior to infection. The cells were harvested at $24 \mathrm{~h}$ post-infection (hpi). For early (E) RNA, phosphonoacetic acid $(100 \mu \mathrm{g} / \mathrm{ml})$ was added immediately after infection and the cells were harvested at 48 hpi. Late (L) RNA and mock-infected cellular RNA were derived from infected and uninfected cells, respectively, cultured in parallel and harvested at $96 \mathrm{hpi}$.

Total RNA was isolated from $\sim 1 \times 10^{7} \mathrm{HCMV}$-infected HELF cells by TRIzol reagent (Invitrogen/Life Technologies, Shanghai, China) using the classic phenol/chloroform methods, and then dissolved in $50 \mu \mathrm{l}$ RNase-free $\mathrm{H}_{2} \mathrm{O}$, using the TURBO DNA-free ${ }^{\mathrm{TM}}$ kit (Ambion/Life Technologies, Austin, TX, USA). The integrity of the RNA was analyzed by $1 \%$ agarose gel electrophoresis.

cDNA preparations of HCMV non-infected HELF cells and HCMV infected HELF cells from the IE, E and L phases were carried out using the 3'-Full RACE Core Set kit (Takara, Dalian, China). Reverse transcription was performed with $1 \mu \mathrm{g}$ RNA and an oligo(dT)3 site adaptor, which was provided in the kit, introducing a special sequence into the 5 -terminal of the cDNA, according to instructions provided by the manufacturer.

Hybrid-PCR and BLAST for candidate target genes. Target genes of homv-miR-UL148D were screened using the hybridPCR method as described in a previous study of ours (27). The hybrid-PCR primer of hcmv-miR-UL148D, A1, was designed according to the reverse sequence of hcmv-miR-UL148D (Fig. 1A). A semi-nested PCR was performed using primer A1 as the forward primer and the primer A2/A3 provided in the 3'-Full RACE Core Set kit (Takara) as the reverse primer. All primers used in this study are listed in Table I. The purified PCR products were T-A cloned and the clones were randomly selected for sequencing analysis using the ABI PRISM 3700 DNA sequencer (Applied Biosystem/Life Technologies, Carlsbad, CA, USA).
The candidate target sequences of hcmv-miR-UL148D were blasted on line (http://www.ncbi.nlm.nih.gov/blast) using the mRNA specific sequences located between primer A1 (i.e., the binding site) and poly A obtained from hybrid-PCR. Putative target genes were identified according to the following sequence criteria: i) containing a sequence either completely complementary to the homv-miR-UL148D seed region or with only one base unpaired; ii) the homv-miR-UL148D binding site is located within the 3' untranslated region (3'UTR) or coding domains (CDS) of the putative target genes; and iii) containing a poly A structure, which indicates that the sequences originate from mRNA.

Plasmid construction and site-directed mutagenesis. According to the sequence of the Han strain, the primers for construction of the hcmv-miR-UL148D expression plasmid (pSilence-homv-mir-UL148D) were designed as primer-B1/B2. The purified PCR products of the hcmv-mir-UL148D encoding sequence were inserted into the pSilencer 4.1 vector (Ambion/ Life Technologies) between the BamHI and the HindIII sites. The selected clone was confirmed by sequencing analysis.

As the control of the homv-miR-UL148D expression plasmid, the plasmid with a full-length mutation at the seed region of hcmv-miR-UL148D was obtained using site-directed mutagenesis. The mutant plasmid was firstly synthesized based on a PCR amplification with 2 primers $(\mathrm{C} 1 / \mathrm{C} 2)$ designed for the specific nucleotide mutation, $p f u$ DNA polymerase (Takara), and the wild-type pSilence-homv-mir-UL148D as the template. The PCR products were then treated with methylase $D p n \mathrm{I}$ at $37^{\circ} \mathrm{C}$ for $1 \mathrm{~h}$ to exclude the original plasmid of pSilence-hcmv-mir-UL148D, methylated during replication in Escherichia coli. Finally, the mutant plasmid was transformed into Escherichia coli DH5a to repair the nicks in the mutant plasmid resulting from the synthesized step. Clones were randomly selected, and the mutant plasmid, pSilence-homvmir-UL148D-mutant, was confirmed by sequencing analysis.

For dual luciferase report assays, the full-length 3'UTR sequence of IEX-1 was inserted into the pMIR vector at the SpelI and the HindIII sites to construct pMIR-IEX-1-3'UTR. The primers for amplification of the IEX-1-3'UTR sequence were D1/D2. As an inner control, the pMIR-IEX-1-3'UTR-mutant with the whole mutant binding site of the hcmv-miR-UL148D seed region in the IEX-1-3'UTR was obtained by site-directed mutageneisis as described above. The primer sequences for the mutagenesis of the IEX-1-3'UTR sequence were E1/E2.

For western blot analysis, the expression plasmid, pBIIEX-1-3'UTR, was constructed by inserting the full-length IEX-1 cDNA with 3'UTR sequence into the pBI vector at the BamHI and HindIII sites. The primer sequences for amplification of the IEX-1 cDNA were F1/F2. The expression plasmid containing the mutant 3 'UTR sequence of IEX-1, pBI-IEX-1-3'UTR-mutant, was obtained by site-directed mutagenesis using the same primers as those used for the construction of the pMIR-IEX-1-3'UTR-mutant plasmid.

For the apoptosis assay, the expression plasmid, pcDNA3.1IEX-1-3'UTR, was constructed by inserting the full-length of IEX-1 cDNA with the 3 'UTR sequence into the pcDNA3.1 vector at the HindIII and BamHI sites. The primer sequences were G1/G2. The control plasmid, pcDNA3.1-IEX-1-3'UTRmutant, was obtained by site-directed mutagenesis using the 
Table I. Names and sequences of primers used in this study.

\begin{tabular}{|c|c|c|}
\hline Primer names & Primer sequences & Use of the primers \\
\hline A1 & 5'-gcggtgaagaaggggaggacg-3', & Hybrid-PCR \\
\hline A2 & 5'-taccgtcgttccactagtgattt-3' & \\
\hline A3 & 5'-cgcggatcctccactagtgatttcactatacg-3' & \\
\hline B1 & 5'-gcggatccgattctccagggaacgacag-3' & pSilence-hcmv-mir-UL148D \\
\hline B2 & $5^{\prime}$-gcaagcttacaaccgccgctattcttt-3' & \\
\hline $\mathrm{C} 1$ & 5'-ggcggtgaagaagggagacggcacgttctcgccacga-3' & pSilence-hcmv-mir-UL148D-mutant \\
\hline $\mathrm{C} 2$ & 5'-tcgtggcgagaacgtgccgtctccettcttcaccgcc-3' & \\
\hline D1 & 5'-gcactagtctgtgactcccegcactc-3' & pMIR-IEX-1-3'UTR \\
\hline D2 & 5'-gcaagcttcacagtagacagacggagttga-3' & \\
\hline E1 & 5'-aggactcgggtggggagacggctcccggctgggatga-3' & pMIR-IEX-1-3'UTR-mutant \\
\hline $\mathrm{E} 2$ & 5'-tcatcccagccgggagccgtctccccacccgagtcct-3' & \\
\hline $\mathrm{F} 1$ & 5'-cgcggatccatgtgtcactctcgcagctgcc-3' & pBI-IEX-1-3'UTR \\
\hline $\mathrm{F} 2$ & $5^{\prime}$-cccaagctttgtgttcacagaacatactaggc-3' & \\
\hline G1 & $5^{\prime}$-cccaaggcttatgtgtcactctcgcagctgcc-3' & pcDNA3.1-IEX-1-3'UTR \\
\hline $\mathrm{G} 2$ & 5'-cgcggatcctgtgttcacagaacatactaggc-3' & \\
\hline
\end{tabular}

primers, E1/E2, which were the same as those used for the construction of the pMIR-IEX-1-3'UTR-mutant plasmid.

Dual luciferase reporter assays. To evaluate the binding effect of homv-miR-UL148D to the 3'UTR of IEX-1, a dual-luciferase reporter assay (Promega, Madison, WI, USA) was carried out, with a pRL-TK plasmid as the control for transfection efficiency.

A group of plasmids, pSilence-hcmv-miR-UL148D (600 ng), pMIR-IEX-1-3'UTR (100 ng) and pRL-TK (100 ng), was co-transfected into the HEK293 cells using Lipofectamine 2000 (Invitrogen/Life Technologies) according to the manufacturer's instructions in a 24-well culture plate. The miRNA control, consisting of pSilence-hcmv-miR-UL148D-mutant (600 ng), pMIR-IEX-1-3'UTR (100 ng) and pRL-TK (100 ng), and the IEX-1-3'UTR control, containing pSilence-hcmv-miR-UL148D (600 ng), pMIR-IEX-1-3'UTR-mutant (100 ng) and pRL-TK $(100 \mathrm{ng})$, were transfected at the same time. After $48 \mathrm{~h}$, the cells were harvested for the detection of the luciferase activity using a luminometer (Berthold Technologies, Oak Ridge, TN, USA) according to the manufacturer's instructions. The normalized firefly luciferase activity to that of Renilla was used to evaluate the binding effect of hcmv-miR-UL148D with the 3'UTR of IEX-1. The experiments were carried out at least 3 times.

Western blot analysis. To detect the expression kinetics of the IEX-1 protein during HCMV infection, the HELF cells were incubated with the Han strain and treated by cycloheximide and phosphonoacetic acid, as described above. Cellular proteins were extracted from the mock-infected and HCMV-infected cells at the IE, E and L stages using cytoplasmic protein lysis buffer (50 mM Tris, PH 7.5, 10\% glycerol, $150 \mathrm{mM} \mathrm{NaCl}$, $1 \mathrm{mM}$ EDTA, $1 \%$ Triton X-100 and protease and phosphatase inhibitors). Protein concentrations were determined using the BCA Protein Assay kit (P0012; Beyotime, Nantong, China). Equal amounts of proteins were separated by sodium dodecyl sulfate-polyacrylamide gel electrophoresis and transferred onto a polyvinylidene fluoride membrane at $4^{\circ} \mathrm{C}$. The membranes were subsequently incubated with primary antibody to IEX-1 (1:1,000; ab65152; Abcam, Cambridge, UK) or $\beta$-actin $(1: 1,000$; SC-1615; Santa Cruz Biotechnology, Inc., Santa Cruz, CA, USA), followed by incubation with HRP-conjugated secondary antibody (1:2,000; Beijing Zhongshan Biotechnology Co., Beijing, China). Luminescence was visualized on a Bio-Rad image station.

In order to detect the effects of hcmv-mir-UL148D on IEX-1 expression, the HEK293 cells in 60-mm culture plate were co-transfected using Lipofectamine 2000 with the miRNA expression plasmid, pSilence-hcmv-mir-UL148D, and the IEX-1 expression plasmid, pBI-IEX-1-3'UTR, or its mutant plasmid, pBI-IEX-1-3'UTR-mutant. At the same time, the HEK293 cells were co-transfected with the IEX-1 expression plasmid, pBI-IEX-1-3'UTR, and the miRNA expression plasmid, pSilence-hcmv-mir-UL148D, or its mutant plasmid, pSilence-hcmv-mir-UL148D-mutant. The cells were harvested at $48 \mathrm{~h}$ after transfection. The expression of IEX-1 was detected by western blot analysis using primary antibodies to IEX-1 and green fluorescent protein (GFP), which was expressed by the $\mathrm{pBI}$ vector and served as the internal control, separately.

Apoptosis assay. HEK293 cells cultured in a 6-well culture plate were first transfected using Lipofectamine 2000 with the miRNA expression plasmid, pSilence-hcmv-mir-UL148D (3,600 ng), or its mutant plasmid, pSilence-hcmv-mirUL148D-mutant (3,600 ng). After $24 \mathrm{~h}$, the cells were further transfected with the IEX-1 expression plasmid, pcDNA3.1IEX-1-3'UTR (400 ng). The HEK293 cells transfected with the miRNA expression plasmid, pSilence-hcmv-mir-UL148D, or its mutant plasmid, pSilence-hcmv-mir-UL148D-mutant, were further transfected with the IEX-1 mutant expression plasmid, pcDNA3.1-IEX-1-3'UTR-mutant. Cells were harvested at $48 \mathrm{~h}$ after transfection, and washed with PBS buffer. The 
recovered cells were then analyzed for apoptosis using the Annexin V-FITC apoptosis detection kit (c1063; Beyotime) following the procedures outlined by the manufacturer on a flow cytometer (FACSCalibur; BD Biosciences, Franklin Lakes, NJ, USA).

Prediction of binding sites of HCMV encoding miRNAs in IEX-1 using Biosoftware RNAhybrid-Submission. To analyze whether IEX-1 can be regulated by other miRNAs encoded by HCMV, a Biosoftware RNAhybrid-Submission (http://bibiserv. techfak.uni-bielefeld.de/rnahybrid/submission.html) was used. The binding sites of HCMV encoding miRNAs in IEX-1 were identified according to the following miRNA selection criteria: i) $>6$ nts in its seed region were complementary to the IEX-1$3^{\prime} \mathrm{UTR}$; ii) the minimum free energy (mfe) of the binding was $<-20 \mathrm{kcal} / \mathrm{mol}$.

Statistical analysis. Data are expressed as the means \pm SD. Statistical analysis was carried out using the two-tailed, unpaired Student's t-test. A level of $\mathrm{P}<0.05$ was considered to indicate a statistically significant difference.

\section{Results}

Putative target genes of hcmv-miR-UL148D screened by hybrid-PCR. Since miRNAs exhibit post-trancriptional regulatory effects by binding to target mRNAs, the target mRNA sequences were screened within mRNA-derived cDNA from HCMV-infected cells using hybrid-PCR, which has been experimentally demonstrated to be efficient for screening target genes of any known miRNAs (27). Two main products of hemv-mir-UL148D obtained from the HCMV-infected cells by hybrid-PCR were $\sim 300$ and $500 \mathrm{bp}$ in length. Of note, the $\sim 300$ bp fragment was stronger in the IE phase of the HCMVinfected cells than in the $\mathrm{E}$ and $\mathrm{L}$ phase cells, as well as in the non-infected cells (Fig. 1B).

The $\sim 300$ bp fragment was subsequently cloned by the T-A clone method, and the inserts of 11 clones were successfully sequenced. Using BLAST analysis, 9 of them contained sequences homologous to the cellular gene, IEX-1 with the length of $297 \mathrm{bp}$ from $968 \mathrm{nt}$ to the polyA signal of IEX-1 mRNA. The sequence of the 3'UTR of IEX-1 mRNA from 968 to $978 \mathrm{nt}$ was completely complementary to the $11 \mathrm{nt}$ sequence of the hcmv-miR-UL148D seed region; while its upward sequence was partially complementary to the other $10 \mathrm{nt}$ sequence in the 3 '-terminal of homv-mir-UL148D (Fig. 1C). Therefore, IEX-1 was preferentially considered to be the candidate target gene of homv-miR-UL148D.

Binding ability of homv-mir-UL148D to 3'UTR of the IEX-1 $m R N A$. The entire wild-type and mutant 3'UTR of IEX-1 were inserted downstream of the luciferase gene. The results of dual-luciferase reporter assays showed that compared with the mutant homv-miR-UL148D, hcmv-miR-UL148D suppressed the relative luciferase activity of pMIR-IEX-1-3'UTR by $\sim 47 \%$; the relative luciferase activity of pSilence-hcmv-miR-UL148D was suppressed $\sim 40 \%$ by the wild-type plasmid compared to the control pMIR-IEX-1-3'UTR-mutant plasmid (Fig. 2A). These results suggest that the binding site at 952 to 979 nt of IEX-13'UTR may be specifically affected by homv-miR-UL148D.
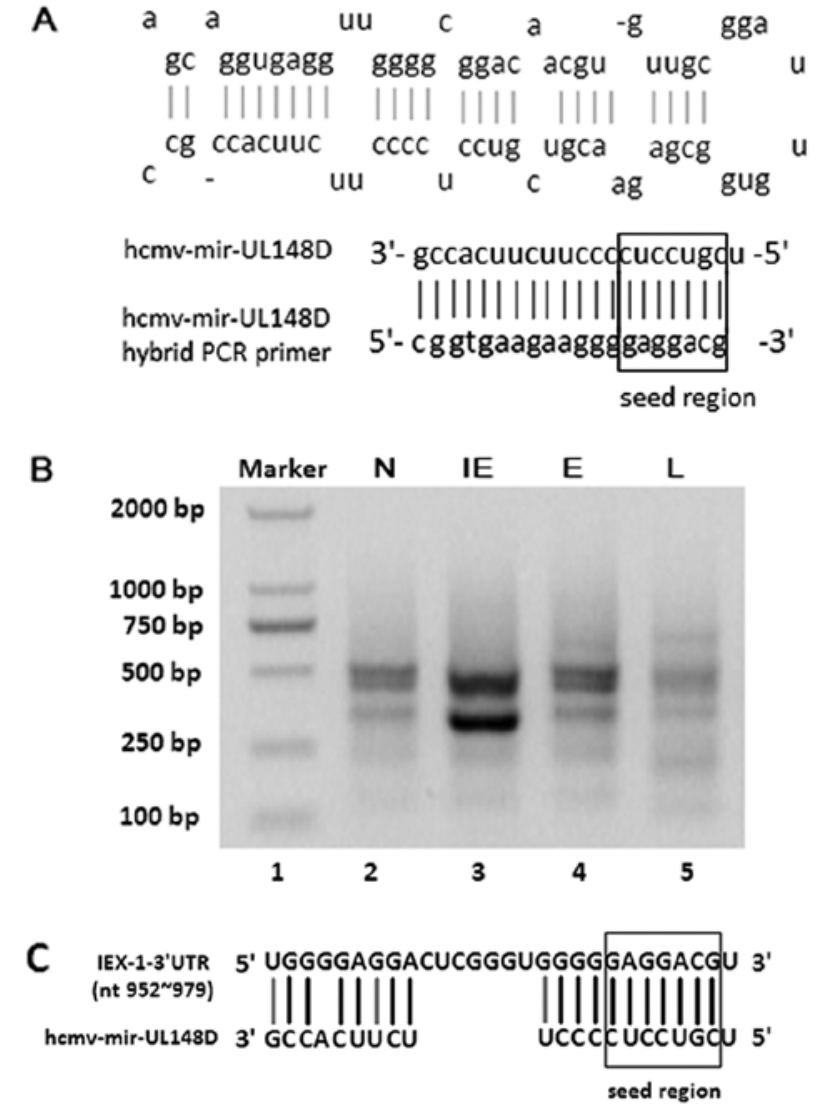

Figure 1. (A) Stem-loop structure of human cytomegalovirus (HCMV) miR-UL148D and sequence of designed hyprid-PCR primer. (B) Hybrid-PCR results of hcmv-mir-UL148D. Lanes 2-5 indicate the products of Hybrid-PCR carried out in various cDNA from normal HELF cells (line 2), and HELF cells infected with HCMV at the IE (line 3), E (line 4) and L (line 5) phase with primers designed for hcmv-mir-UL148D hybrid-PCR. (C) The binding site of hcmv-mir-UL148D in IEX-1-3'UTR.

Expression kinetics of IEX-1 during HCMV infection. To examine the downregulatory effect of hcmv-mir-UL148D on the cellular gene, IEX-1, the expression kinetics of IEX-1 during HCMV infection were primarily detected using proteins from cells infected with the Han strain by western blot analysis. In cells collected at the IE and E phase, a slight IEX-1 expression band was detected; while in cells at the L phase cells or mockinfected HELF cells, no IEX-1 expression was detected. The expression level of IEX-1 in cells at the E phase was only $10 \%$ of that in cells at the IE phase. This divergence in expression levels suggested that IEX-1 expression was elevated during HCMV infection at the IE phase, and was downregulated gradually at the $\mathrm{E}$ and L phase (Fig. 2B).

Suppression of IEX-1 gene expression by homv-miR-UL148D. In order to further evaluate the specific effect of homv-mirUL148D on the expression of IEX-1, an in vitro system was utilized. HEK293 cells were transfected with IEX-1 and homv-mir-UL148D. The western blot analysis results showed that compared with mutant hcmv-miR-UL148D, hcmv-miRUL148D suppressed the expression of pBI-IEX-1-3'UTR $\sim 43 \%$; the expression was suppressed $\sim 47 \%$ compared with the expression of pBI-IEX-1-3'UTR-mutant together with 

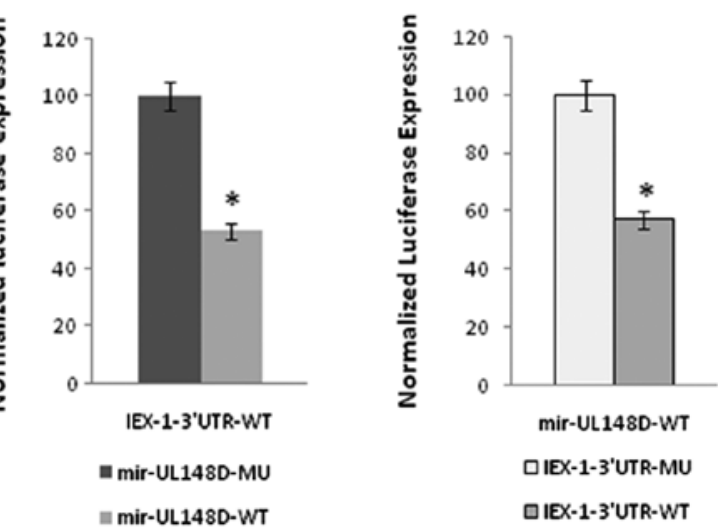

B
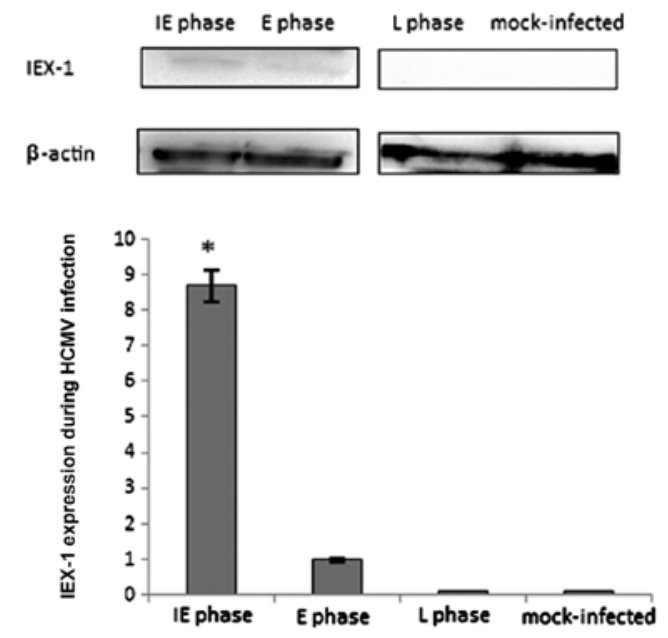

C
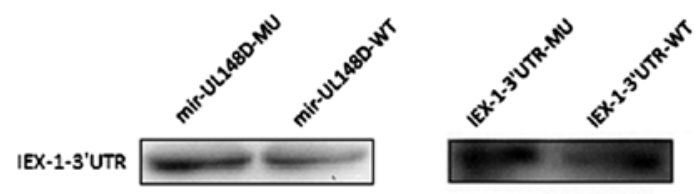

PBI-GFP
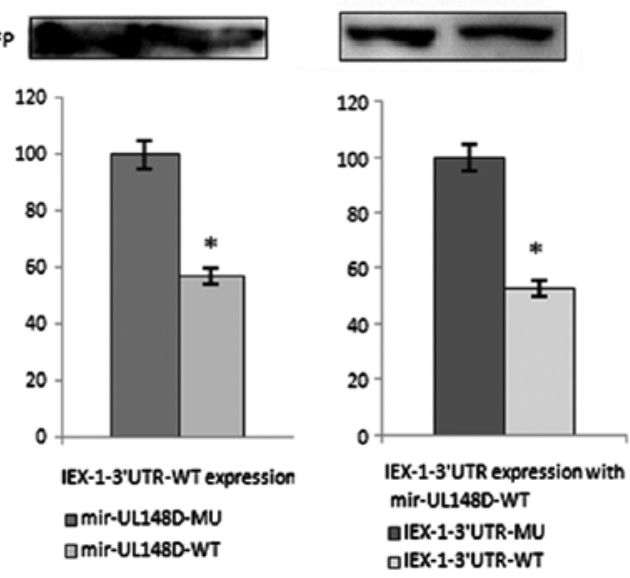

Figure 2. (A) The results of dural-luciferase reporter assay showed that homvmir-UL148D has the ability to bind to the 3'UTR of IEX-1. (B) The results of western blot analysis showed the kinetics of IEX-1 expression at differen HCMV infection phases. (C) The results of western blot analysis showed the inhibitory effects of hemv-mir-UL148D on the expression of IEX-1. MU, mutant molecules; WT, wild-type molecules.

pSilence-hcmv-mir-UL148D (Fig. 2C). These results suggest that hcmv-miR-UL148D can functionally downregulate IEX-1 expression.
hcmv-miR-UL148D exerts anti-apoptotic effects by downregulating IEX-1 expression. In order to identify the effects of hcmv-mir-UL148D on cell apoptosis caused by ectopically expressed IEX-1, HEK293 cells were first transfected with pSilence-homv-mir-UL148D followed by the IEX-1 expression plasmid, pcDNA3.1-IEX-1-3'UTR. The percentage of apoptotic cells in the cells transfected with the expression plasmids of hcmv-mir-UL148D and IEX-1 was decreased $\sim 51 \%$ compared with the control cells expressing mutant hcmv-mir-UL148D and IEX-1 with a normal 3'UTR; the percentage was decreased 54\% compared with the cells expressing homv-mir-UL148D and IEX-1 with a mutant 3'UTR (Fig. 3). These results indicate that hemv-mir-UL148D exerts anti-apoptotic effects by downregulating the elevated expression of the cellular gene, IEX-1, during HCMV infection.

Prediction of binding sites of HCMV encoding miRNAs in IEX-1 by Biosoftware RNAhybrid-Submission. Multiple HCMV miRNAs were predicted to be partially complementary to IEX-1-3'UTR with the mfe $<-20 \mathrm{kcal} / \mathrm{mol}$ (Fig. 4). The hcmv-mir-UL148D binding site at 952-979 nt in the IEX-1 gene is located $23 \mathrm{nt}$ upstream of the predicted binding site of homv-mir-UL22A (975-1004 nt), and $21 \mathrm{nt}$ upstream of one of the binding sites of homv-mir-UL70 (973-993 nt) predicated by Biosoftware RNAhybrid-Submission. The binding sites in IEX-1-3'UTR of these miRNA were located separately $>21 \mathrm{nt}$ from each other.

\section{Discussion}

Since miRNAs have been found to be expressed in a number of viruses and exert downregulatory effects on target gene expression, the study of miRNAs may provide further insight into the mechanisms of viral pathogenesis and host defense. The determination of target genes and the relative functions of a given miRNA have been the new research highlights. A recent study showed that homv-mir-UL148D, concomitant with other miRNAs encoded by HCMV, is expressed in low-passage clinical strains recovered from the amniotic fluid and urine of congenitally-infected infants (26). In the present study, the cellular target gene, IEX-1, of hcmv-mir-UL148D, which resides in the HCMV UL/b' region only found in clinical isolates, was identified by a series of experiments.

To date, the prediction of viral miRNA targets has been particularly challenging due to the complex prediction algorithms (28) and the high false-positive rate (29). The hybrid-PCR method used in our study has proven to be a useful experimental method for screening putative target genes of any known miRNA (27). It conforms to the idea that only the seed region of the miRNA is completely complementary to and/or other sequences partially complementary to the target mRNA, and that this miRNA can exhibit a translational inhibitory effect. In fact, the more completely complementary the nucleotides (nts) in the 3'-terminal sequence of a hybrid-PCR primer, the stronger the binding of the miRNA to the target mRNA, and the easier it will be for the targets to be amplified by the hybrid-PCR method.

The main hybrid-PCR product of homv-mir-UL148D in the IE, $E$ and $L$ phases of the HCMV infected cells was $\sim 300$ bp in length. This band was confirmed to be derived from the cellular 

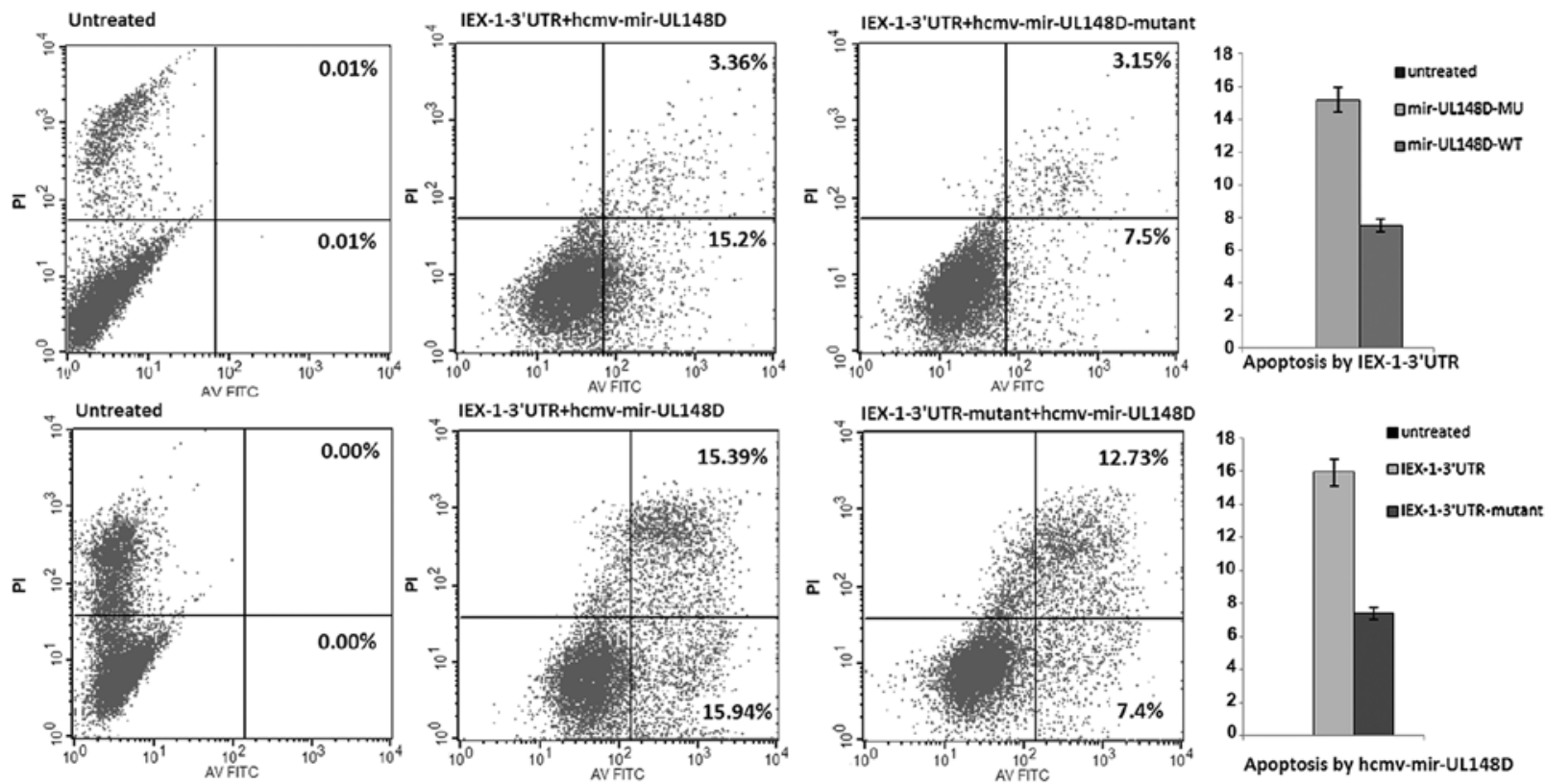

Figure 3. Apoptosis assay using an in vitro system to evaluate the anti-apoptotic effects of hcmv-mir-UL148D. MU, mutant molecules; WT, wild-type molecules.

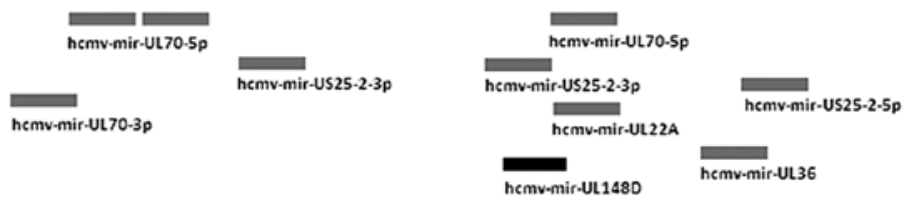

B
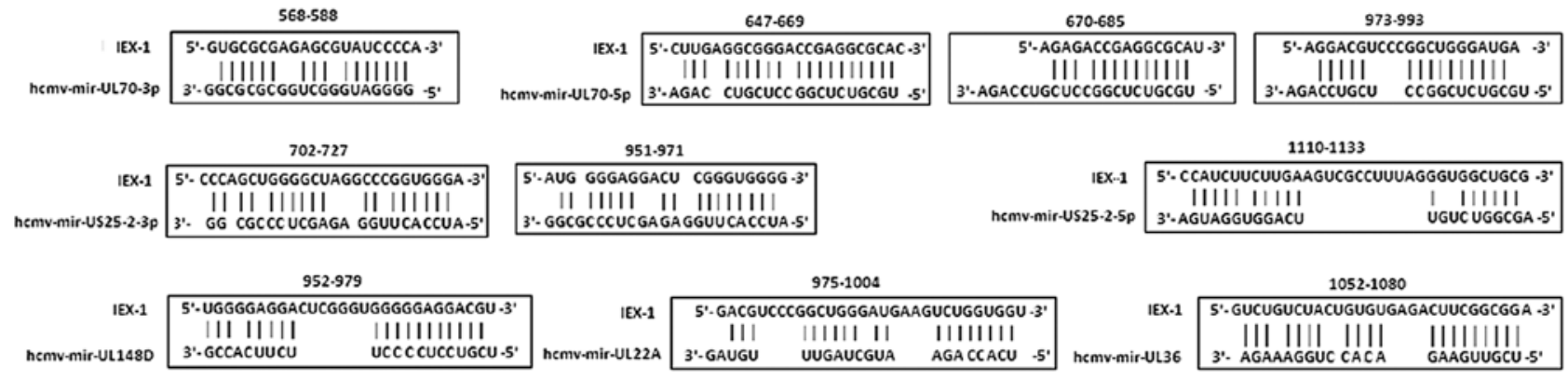

Figure 4. (A) The identified binding site of homv-mir-UL148D to the 3'UTR sequence from 952 to 979 nt of the putative target gene, IEX-1. The black bar indicates the hcmv-mir-UL148D binding site, while the grey bars indicate the binding sites of the other HCMV encoding miRNAs. (B) The predicted binding sites in the IEX-1-3'UTR of HCMV miRNAs by Biosoftware TargetScan. The stable complementation is indicated by a black bar, while the unstable G:U complementation is shown by a grey bar.

gene, IEX-1, by sequencing analysis. A total of 11 nts around the homv-mir-UL148D seed region were complementary to the IEX-1-3'UTR. It has been reported that the complementary sequence between $6 \mathrm{nt}$ of the miRNA seed region and its target sequence is enough to form stable bindings (30). The prediction results by Biosoftware RNAhybrid-Submission in the present study showed that only one binding site from 952 to 979 nt of IEX-1 was satisfactory with consecutive $11 \mathrm{nt}$ pairs completely complementary to hcmv-mir-UL148D 5' end including the entire seed region, and the mfe of this binding was $-35.0 \mathrm{kcal} / \mathrm{mol}$. This predicted binding site was the same as that screened by hybrid-PCR. The high thermodynamic stability of hemv-mir-UL148D:IEX-1-3'UTR suggests that the sequence from 952 to 979 nt of IEX-1 should be the real binding site of homv-mir-UL148D. As shown by luciferase assay, the relative luciferase activity of pMIR-IEX-1-3'UTR was suppressed $\sim 47 \%$ by hcmv-miR-UL148D, compared to the mutant control plasmids of homv-mir-UL148D and IEX-13'UTR. This evidence further demonstrates the binding ability of hemv-mir-UL148D to IEX-1-3'UTR. 
The coding sequence of homv-mir-UL148D resides in the antisense strand of UL150, and is completely complementary to the UL150 sequence. Unfortunately, the exact function of the UL150 gene remains unknown, which hinders the determination of the exact bio-behavioral effects of hemv-mir-UL148D interference. However, the UL150 gene was not identified as a candidate target of homv-mir-UL148D in our screening tests by hybrid-PCR. This may due to a number of resons: i) The number of selected clones was too limited to contain all the putative target genes. ii) The extracted RNAs used in hybrid-PCR contained two genomes, Homo sapiens and HCMV. The higher amount of Homo RNAs than HCMV RNAs in the hybrid-PCR samples made cellular RNAs easier to be amplified.iii) Residing in the high GC region, the UL150 gene is more difficult to be amplified with hybrid-PCR primer and oligo(dT)-3' site adaptor primer at the annealing temperature of $37^{\circ} \mathrm{C}(27)$.

Although the 3'UTR sequence of IEX-1 mRNA from 952 to $979 \mathrm{nt}$ was not completely complementary to the whole sequence of hcmv-mir-UL148D, it was completely complementary to the entire seed region. To determine whether the binding of homv-mir-UL148D to the 3'UTR sequence of IEX-1 mRNA has functional effects on IEX-1 expression, western blot analysis was performed. As shown by western blot analysis, the inhibitory effect of ectopically expressed IEX-1 was similar to that of the suppression of relative luciferase activity as shown by luciferase assay. These results further suggests that the cellular gene, IEX-1, is one of the targets of hcmv-mir-UL148D.

Previous studies have shown that a miRNA may exert synergistic post-regulatory inhibitory effects on a target gene with multiple binding sites (31-33). As shown by western blot analysis, the similar expression levels of IEX-1 in the parallel tests of mutant hemv-mir-UL148D and wild-type IEX-1 with that in tests of wild-type hemv-mir-UL148D and mutant IEX-1 suggest that the binding site in the 3'UTR of IEX-1 mRNA from 952 to $979 \mathrm{nt}$ is an exclusive site.

IEX-1 plays a role in controling apoptosis and cellular growth. IEX-1 expression can be rapidly induced in various cells by irradiation, viral infection, inflammatory cytokines, chemical carcinogens, growth factors and hormones. The increased expression of IEX-1 has been associated with an increase in the growth rate of keratinocytes and HeLa cells, and the disruption of IEX-1 expression in HeLa and 293 cells has been associated with a decrease in cellular proliferation (34-37). A previous study on the hemv-mir-UL148D expression kinetics showed that the expression is first evident at the IE phase, and gradually increases at the $\mathrm{E}$ phase and reaches maximum levels at the L phase during HCMV infection (25). In our study, the weak expression of IEX-1 was detected in the IE phase and the expression was even weaker in the E phase of HCMV infection, but not in cells in the L phase and mock-infected cells, as shown by western blot analysis. The elevated expression of IEX-1 at the IE phase of HCMV infection is likely due to viral invasion. The expression level of IEX-1 in HCMV-infected cells negatively correlates with that of hemv-mir-UL148D. This may partially due to the specific downregulatory effect hcmv-mir-UL148D on IEX-1 expression, which was identified in our in vitro system.

Apoptosis is an antiviral defense mechanism by which the host can eliminate infected cells and restrict viral propagation. It has been demonstrated that HCMV-encoded proteins, such as UL37, an immediately early gene product, can prevent or attenuate apoptosis in infected cells (38-40). By utilizing an in vitro apoptosis assay we demonstrated primarily that homv-mir-UL148D suppresses the apoptotic cells ratio by downregulating IEX-1 expression. The downregulation rate of IEX-1 expression by hemv-mir-UL148D in this in vitro system was $\sim 50 \%$, which was lower than the decreased level of IEX-1 expression from the IE to E phase during HCMV infection (90\%). Certain studies have shown that multiple miRNAs may display cooperative effects on one target (31-33). To explain this result, the binding sites of HCMV other miRNAs in the IEX-1 sequence were analyzed using Biosoftware RNAhybridSubmission. The prediction result showed that multiple miRNAs were partially complementary to IEX-1-3'UTR with the $\mathrm{mfe}<-20 \mathrm{kcal} / \mathrm{mol}$ (Fig. 4). The binding sites in the IEX-1-3'UTR of these miRNA were located separately $>21 \mathrm{nt}$ from each other. This result suggests that multiple miRNAs may cooperatively suppression on IEX-1 expression during HCMV infection. These results may explain the manifestation that the downregulation rate of ectopically expressed IEX-1 by homv-mir-UL148D is lower than the decreased level of IEX-1 expression from the IE to the E phase during HCMV infection. The cooperative effect on IEX-1 expression exerted by homvmir-UL148D and other miRNAs encoded by HCMV and their anti-apoptotic effects require further study.

In conclusion, in the current study, we demonstrate that the expression of the cellular gene, IEX-1, increased at the IE phase, and rapidly decreased at the $\mathrm{E}$ and $\mathrm{L}$ phases during HCMV infection. Hemv-mir-UL148D, a miRNA residing in the HCMV UL/b' region, was identified to downregulate IEX-1 expression through only one binding site within the 3'UTR, and to contribute to the anti-apoptotic effects caused by ectopically expressed IEX-1 in an in vitro system. These findings provide new insight into IEX-1 expression kinetics during HCMV infection, as well as the interactions between homv-miR-UL148D and IEX-1 expression.

\section{Acknowledgements}

This study was supported by the National Natural Science Foundation of China (30672248, 30901625, 81171580 and 81171581) and the Specialized Research Fund for the Doctoral Program of Higher Education (20112104110012) and the Outstanding Scientific Fund of Shengjing Hospital.

\section{References}

1. Griffiths PD, Cope AV, Hassan-Walker AF and Emery VC: Diagnostic approaches to cytomegalovirus infection in bone marrow and organ transplantation. Transpl Infect Dis 1: 179-186, 1999.

2. Dolan A, Cunningham C, Hector RD, et al: Genetic content of wild-type human cytomegalovirus. J Gen Virol 85: 1301-1312, 2004.

3. Cha TA, Tom E, Kemble GW, Duke GM, Mocarski ES and Spaete RR: Human cytomegalovirus clinical isolates carry at least 19 genes not found in laboratory strains. J Virol 70: 78-83, 1996.

4. Dunn W, Chou C, Li H, et al: Functional profiling of a human cytomegalovirus genome. Proc Natl Acad Sci USA 100: 14223-14228, 2003.

5. Ashiru O, Bennett NJ, Boyle LH, Thomas M, Trowsdale J and Wills MR: NKG2D ligand MICA is retained in the cis-Golgi apparatus by human cytomegalovirus protein UL142. J Virol 83: 12345-12354, 2009. 
6. Bennett NJ, Ashiru O, Morgan FJ, et al: Intracellular sequestration of the NKG2D ligand ULBP3 by human cytomegalovirus. J Immunol 185: 1093-1102, 2010.

7. Prod'homme V, Sugrue DM, Stanton RJ, et al: Human cytomegalovirus UL141 promotes efficient downregulation of the natura killer cell activating ligand CD112. J Gen Virol 91: 2034-2039, 2010.

8. Poole E, Groves I, MacDonald A, Pang Y, Alcami A and Sinclair J: Identification of TRIM23 as a cofactor involved in the regulation of NF-kappaB by human cytomegalovirus. J Virol 83: 3581-3590, 2009

9. Poole E, Atkins E, Nakayama T, Yoshie O, Groves I, Alcami A and Sinclair J: NF-kappaB-mediated activation of the chemokine CCL22 by the product of the human cytomegalovirus gene UL144 escapes regulation by viral IE86. J Virol 82: 4250-4256, 2008.

10. Montag C, Wagner JA, Gruska I, Vetter B, Wiebusch L and Hagemeier C: The latency-associated UL138 gene product of human cytomegalovirus sensitizes cells to tumor necrosis factor alpha (TNF-alpha) signaling by upregulating TNF-alpha receptor 1 cell surface expression. J Virol 85: 11409-11421, 2011.

11. Ambros V: The functions of animal microRNAs. Nature 431: 350-355, 2004.

12. Kloosterman WP and Plasterk RH: The diverse functions of microRNAs in animal development and disease. Dev Cell 11: 441-450, 2006

13. Zhao Y and Srivastava D: A developmental view of microRNA function. Trends Biochem Sci 32: 189-197, 2007.

14. Grey F, Antoniewicz A, Allen E, Saugstad J, McShea A, Carrington JC and Nelson J: Identification and characterization of human cytomegalovirus-encoded microRNAs. J Virol 79: 12095-12099, 2005.

15. Hutvagner G and Zamore PD: A microRNA in a multiple-turnover RNAi enzyme complex. Science 297: 2056-2060, 2002.

16. Hammond SM, Bernstein E, Beach D and Hannon GJ: An RNA-directed nuclease mediates post-transcriptional gene silencing in Drosophila cells. Nature 404: 293-296, 2000.

17. Mourelatos Z, Dostie J, Paushkin S, et al: miRNPs: a novel class of ribonucleoproteins containing numerous micro-RNAs. Genes Dev 16: 720-728, 2002.

18. Bartel DP: MicroRNAs: genomics, biogenesis, mechanism, and function. Cell 116: 281-297, 2004.

19. Brennecke J, Stark A, Russell RB and Cohen SM: Principles of microRNA-target recognition. PLoS Biol 3: e85, 2005.

20. Doench JG and Sharp PA: Specificity of microRNA target selection in translational repression. Genes Dev 18: 504-511, 2004

21. Tuddenham $\mathrm{L}$ and Pfeffer S: Roles and regulation of microRNAs in cytomegalovirus infection. Biochim Biophys Acta 1809: 613-622, 2011

22. Stern-Ginossar N, Elefant N, Zimmermann A, et al: Host immune system gene targeting by a viral miRNA. Science 317 376-381, 2007.

23. Grey F, Meyers H, White EA, Spector DH and Nelson J: A human cytomegalovirus-encoded microRNA regulates expression of multiple viral genes involved in replication. PLoS Pathog 3: e163, 2007.

24. Kim S, Lee S, Shin J, et al: Human cytomegalovirus microRNA miR-US4-1 inhibits CD8(+) T cell responses by targeting the aminopeptidase ERAP1. Nat Immunol 12: 984-991, 2011.
25. Kim Y, Lee S, Kim S, Kim D, Ahn JH and Ahn K: Human cytomegalovirus clinical strain-specific microRNA miR-UL148D targets the human chemokine RANTES during infection. PLoS Pathog 8: e1002577, 2012.

26. Stern-Ginossar N, Saleh N, Goldberg MD, Prichard M, Wolf DG and Mandelboim O: Analysis of humancytomegalovirus-encoded microRNA activity during infection. J. Virol 83: 10684-10693, 2009.

27. Huang Y, Qi Y, Ruan Q, Ma Y, He R, Ji Y and Sun Z: A rapid method to screen putative mRNA targets of any known microRNA. Virol J 8: 8, 2011.

28. Rajewsky N: microRNA target predictions in animals. Nat Genet 38: S8-S13, 2006

29. Baek D, Villén J, Shin C, Camargo FD, Gygi SP and Bartel DP: The impact of microRNAs on protein output. Nature 455: 64-71, 2008.

30. Bentwich I: Prediction and validation of microRNAs and their targets. FEBS Lett 579: 5904-5910, 2005.

31. Tirabassi R, Hook L, Landais I, Grey F, Meyers H, Hewitt H and Nelson J: Human cytomegalovirus US7 is regulated synergistically by two virally encoded microRNAs and by two distinct mechanisms. J Virol 85: 11938-11944, 2011.

32. Hon LS and Zhang Z: The roles of binding site arrangement and combinatorial targeting in microRNA repression of gene expression. Genome Biol 8: R166, 2007.

33. Saetrom P, Heale BS, Snøve O Jr, Aagaard L, Alluin J and Rossi JJ: Distance onstraints between microRNA target sites dictate efficacy and cooperativity. Nucleic Acids Res 35: 2333-2342, 2007

34. Arlt A, Grobe O, Sieke A, Kruse ML, Folsch UR, Schmidt WE and Schafer H: Expression of the NF-kappa B target gene IEX-1 (p22/PRG1) does not prevent cell death but instead triggers apoptosis in HeLa cells. Oncogene 20: 69-76, 2001.

35. Kumar R, Kobayashi T, Warner GM, Wu Y, Salisbury JL, Lingle W and Pittelkow MR: A novel immediate early response gene, IEX-1, is induced by ultraviolet radiation in human keratinocytes. Biochem Biophys Res Commun 253: 336-341, 1998.

36. Arlt A, Kruse ML, Breitenbroich M, et al: The early response gene IEX-1 attenuates NF-kappaB activation in 293 cells, a possible counter-regulatory process leading to enhanced cell death. Oncogene 22: 3343-3351, 2003.

37. Schafer H, Arlt A, Trauzold A, Hunermann-Jansen A and Schmidt WE: The putative apoptosis inhibitor IEX-1L is a mutant nonspliced variant of p22(PRG1/IEX-1) and is not expressed in vivo. Biochem Biophys Res Commun 262: 139-145, 1999.

38. Skaletskaya A, Bartle LM, Chittenden T, McCormick AL, Mocarski ES and Goldmacher VS: A cytomegalovirus-encoded inhibitor of apoptosis that suppresses caspase-8 activation. Proc Natl Acad Sci USA 98: 7829-7834, 2001.

39. Hayajneh WA, Colberg-Poley AM, Skaletskaya A, et al: The sequence and antiapoptotic functional domains of the human cytomegalovirus UL37 exon 1 immediate early protein are conserved in multiple primary strains. Virology 279: 233-240, 2001.

40. Goldmacher VS: vMIA, a viral inhibitor of apoptosis targeting mitochondria. Biochimie 84: 177-185, 2002. 